\title{
RESENHA
}

\section{A CONSCIENTIZAÇÃO E O COMPROMISSO PROFISSIONAL PARA A MUDANÇA SOCIAL: REFLEXÕES FREIREANAS}

Lilian Moreira Cruz ${ }^{1}$

O livro Educação e Mudança de autoria de Paulo Freire, foi escrito originalmente em espanhol em 1976 e publicado no Brasil em 1979. O prefácio foi escrito por Moacir Gadotti, grande amigo de Freire. Gadotti nos chama a atenção para a leveza existente no discurso freireano no decorrer do livro. Enfatiza que apesar de Freire ter sido expulso do seu próprio país por quase 15 anos, não permitiu que o exílio marcasse a vida com mágoa ou com nostalgia doentia, pelo contrário, em todos os lugares que Freire viveu fora do Brasil (Chile, Estados Unidos, Suíça, África) levou uma mensagem de esperança, de fé, de otimismo crítico, assim, combateu a opressão. Freire teve uma vida pautada numa práxis autêntica; foi profissional sempre presente no cotidiano da vida concreta.

O tema central da discussão deste livro é a Mudança. Freire coloca o processo de conscientização da sociedade como uma possibilidade de mudança, bem como a importância do compromisso do profissional social com este processo de conscientização através da educação.

O livro apresenta quatro capítulos, a saber: $1^{\mathrm{a}}$. O Compromisso do Profissional com a Sociedade; $2^{\circ}$. A Educação e o Processo de Mudança Social; $3^{\circ}$ O Papel do Trabalhador Social no Processo de Mudança; $4^{\circ}$. Alfabetização de Adultos e Conscientização.

No primeiro capítulo, Freire apresenta a necessidade de o profissional assumir um compromisso social com seu trabalho. Para o referido autor, a primeira condição para isto, é ser capaz de agir e refletir. Essa capacidade torna o homem um ser de práxis. Contudo, “é preciso que seja capaz de, estando no mundo, saber-se nele" (FREIRE, 2018, p. 19). Isso requer um movimento interior de auto percepção, compreender como ser que existe e pode atuar no mundo. Assim, relacionar-se com o mundo, perceber as possibilidades de interagir,

\footnotetext{
${ }^{1}$ Doutoranda em Educação pela Universidade Federal da Bahia (UFBA), Mestra em Educação em Ciências e Matemática pela Universidade Estadual do Sudoeste da Bahia (UESB), Professora Assistente da Universidade Estadual de Santa Cruz (UESC). Grupo de Estudos e Pesquisas em Educação Infantil/UESC. E-mail: lmcruz@uesc.br. Orcid: https://orcid.org/0000-0003-4686-5803.
}

Revista de Estudos em Educação e Diversidade. v. 1, n. 1, p. 111-117, jul./set. 2020. 


\section{Revista de Estudos em Educação e Diversidade}

REED

atuar, analisar, modificar, transformar, refletir, distanciar, entre outras, de acordo as suas necessidades.

É na "atuação-reflexão" que o homem vai vencendo os obstáculos, que porventura surgem. Isso exige um engajamento com compromisso humanizado e consciente com responsabilidade consigo e com os outros. Neste momento, Freire aponta a necessidade de vencer o medo, para também vencer a luta contra o egoísmo, a maldade, a falsa neutralidade das ações e a desumanização.

$\mathrm{O}$ referido autor aponta ainda que o verdadeiro compromisso é sempre solidário. "O verdadeiro compromisso é a solidariedade, e não a solidariedade com os que negam o compromisso solidário, mas com aqueles que, na situação concreta, se encontram convertidos em "coisas" (FREIRE, 2018, p.23).

Freire sugere uma busca constante pela capacitação profissional.

Quanto mais me capacito como profissional, quanto mais sistematizo minhas experiências, quanto mais me utilizo do patrimônio cultural, que é patrimônio de todos e ao qual todos devem servir, mais aumenta minha responsabilidade com os homens. Não posso, por isso mesmo, burocratizar meu compromisso de profissional, servindo, numa inversão dolosa de valores, mais aos meios que ao fim do homem. Não posso me deixar seduzir pelas tentações míticas, entre elas a da minha escravidão às técnicas, que, sendo elaboradas pelos homens, são suas escravas e não suas senhoras (FREIRE, 2018, p. 25).

Ser um profissional é assumir essa postura diariamente, independente de dias, horários e lugares. Não burocratizar o seu acesso, isto é, estar disponível quando requisitado. Tarefa que lhes exige, durante a atuação profissional uma postura ética, democrática e humana. Neste sentindo, é preciso assumir todas as necessidades de ação e reflexão na prática profissional. Uma delas é a busca permanente pelo conhecimento científico, tecnológico, pedagógico, entre outros mais.

Freire inspira reflexões e práticas críticas libertadoras para os profissionais sociais. Incentiva a busca por criticidade para conseguir enxergar o homem em sua totalidade, bem como vencer a alienação e a ingenuidade para assumir um compromisso autêntico. É na ruptura com alienação que compreenderá a inexistência da neutralidade nas ações profissionais.

No segundo capítulo do livro, Freire apresenta a educação como um possível caminho para se operar mudanças numa sociedade, entretanto, o autor diz que é necessário refletir sobre o próprio homem. Destarte, analisá-lo numa dimensão filosófica-antropológica e se perguntar onde se sustenta o processo de educação. Para o autor, existe um núcleo captável 


\section{Revista de Estudos em Educação e Diversidade}

REED

deste processo que é o inacabamento/inconclusão humana. O homem se vê como ser que não está acabado/pronto, por isso se educa. A educação é um processo individual e permanente, isto posto, os educadores precisam incentivar/colaborar o processo da educação para o sujeito perceber sua realidade e suas necessidades educativas, isto é fazer autorreflexão.

Freire ressalta que ninguém educa ninguém; a educação acontece a partir das relações que estabelecemos com o/no mundo. É uma busca pessoal de si mesmo, isto é, “A educação é uma resposta da finitude da infinitude" (FREIRE, 2012, p. 34). Reside aí o cerne do pensamento freireano, o homem precisa ser o sujeito da educação e não o objeto dela.

É através desta busca que construímos nossos saberes e conhecimentos, buscamos colaborar com o rompimento da própria ignorância. Mas não podemos esquecer que o saber é relativo, não há saber absoluto, por isso um educador precisa ser humilde ao ensinar. É necessário eliminar a vaidade das práticas docentes, que dizer, não deve se colocar como superior em relação aos estudantes.

Freire sugere o amor como ferramenta essencial no processo da educação e também na luta contra o egoísmo. Para o referido autor, “ não há educação sem amor”. O amor que ajuda o/a educador/a a compreender o ser humano como inacabado, portanto, como alguém que tem direito de ser respeitado em sua inconclusão. Além do amor, Freire também coloca a esperança como fundamental na educação. "Uma educação sem esperança não é educação" (FREIRE, 2018, p. 37). Para o autor, o trabalho na educação é para quem acredita nela, para quem não acredita precisar procurar labor em outro lugar. A educação carece de profissionais sem medo e com ousadia para se arriscar.

É na educação do ser humano que deve ser estimulada a consciência reflexiva para ele captar e compreender a sua realidade. Mediante está compreensão, ele pode elaborar hipóteses, buscar soluções para possíveis problemas, além de poder transformar sua realidade e construir seu mundo próprio. Nesse ínterim, Freire nos convoca a integrar a realidade, mas não adaptar, pois adaptar é acomodar. Existe, contudo, uma adaptação ativa que permitirá ao homem/mulher ser atuante na realidade que está inserido/a.

Freire ressalta que o ser humano tem um ímpeto criador, portanto, a educação precisa ser estimuladora deste e não restritiva. "A educação é mais autêntica quanto mais desenvolve este ímpeto ontológico de criar" (FREIRE, 2018, p. 41). O/a educador/a que permite ao/a educando/a a oportunidade de criar, recriar, decidir, possibilitará o desenvolvimento da consciência crítica. Entretanto, para realizar essa prática é necessário romper com a sociedade fechada e alienada.

Revista de Estudos em Educação e Diversidade. v. 1, n. 1, p. 111-117, jul./set. 2020. 


\section{Revista de Estudos em Educação e Diversidade}

REED

Freire apresenta algumas características de uma sociedade fechada, sendo está uma sociedade periférica e não reflexiva. Neste tipo de sociedade a elite que comanda, prescreve a vida das classes populares de forma rígida e autoritária. Neste tipo de sociedade, "Não há mobilidade vertical ascendente" (FREIRE, 2018, 43-44). Isso significa que há uma conservação do status ou privilégio da elite.

Já na sociedade alienada é marcada pela imitação de outra, o que conduz na perda da própria identidade. Está sempre se comparando, se inferiorizando, desvalorizando a própria cultura. Freire aponta os perigos deste tipo de sociedade, pois é marcada pela ausência de criticidade.

$\mathrm{Na}$ sociedade alienada, o povo acredita que para ser grande é necessário imitar os outros, assim adotam de outros países modelos de vida, de educação, de cultura, entre outros. Entretanto, não podemos esquecer que somos contemporâneos de um mesmo tempo, mas não das mesmas técnicas. $\mathrm{O}$ que permite compreender, que nem tudo que dá certo num país, dará noutro. Reside aí a necessidade de adaptar, criticar, recriar, reinventar de acordo cada realidade, para não correr o grave risco de culpar o povo de fraqueza ou incapacidade quando os resultados não são positivos.

Freire apresenta também a sociedade em transição, que é aquela que está marcada por nossos valores, pois os antigos não dão conta da necessidade do povo. Contudo, o autor nos chama a atenção para o fato de que "Toda transição é mudança, mas não vice-versa" (FREIRE, 2018, p. 42). Este tipo de sociedade se caracteriza pelo processo de desalienação de valores que não correspondem mais aos anseios sociais. "O velho e o novo têm valor na medida em que são válidos" (FREIRE, 2018, p. 47).

Outra característica da sociedade em transição é a abertura para participação popular, em outras palavras, abertura para o processo de democratização. As massas descobrem seu poder através da educação e passam a exigir mais escolas, mais participação nos processos políticos, saem de uma posição ingênua e assume uma postura revolucionária. Não obstante, a elite cria instituições assistencialistas para domesticar as massas, mantendo assim, o sistema colonialista. Freire $(2018$, p. 49) destaca que "Uma sociedade justa dá oportunidade às massas para que tenham opções e não a opção que a elite tem, mas a própria opção das massas. A consciência criadora e comunicativa é democrática".

Nesse ínterim, o autor critica a educação bancária, que coloca o sujeito na posição passiva de depósito de conhecimento. Sugere uma educação que coloque o homem como ser criador e transformador de sua própria realidade. Assim sendo, é necessário romper com a 


\section{Revista de Estudos em Educação e Diversidade}

REED

consciência ingênua e estimular a consciência crítica. Na consciência ingênua, o homem tem uma visão simplória dos problemas, apresenta respostas baseadas no senso comum, defende o passado como sendo melhor, acredita ser detentor da verdade, o que pode fazê-lo cair no fanatismo, vê a realidade como estática. Já a consciência crítica, o homem utiliza do conhecimento científico para buscar respostas para os problemas da vida, procura testar as descobertas à luz da ciência, busca se libertar dos preconceitos, se coloca como investigador e indagador, reconhece a necessidade de dialogar, respeita os valores velhos e acolhe os novos, sabe que a realidade é dinâmica, ou seja, mutável.

Freire chama a atenção para o fato de que a alienação é um grande obstáculo que o profissional precisará romper para alcançar o compromisso, pois a alienação impede a visão crítica da realidade, não permite ver que não há educação neutra, isto é, não há práticas pedagógicas neutras. Em outras palavras, a alienação impede o ato comprometido, pois o profissional estará sem autonomia, sem criatividade, inseguro, com medo e sob a égide de forças ditatoriais que visam manter o status quo.

No terceiro capítulo da obra, Freire apresenta o trabalhador social como agente fundamental para os processos de mudança de uma estrutura da sociedade. Também salienta que a estrutura social é dinâmica e não estática, se ancora num jogo dialético da mudançaestabilidade, ou seja, no trabalho e na ação que homem exerce sobre o mundo, pois o homem é um ser de práxis.

É necessário reconhecer que para estudar a estabilidade e a mudança, é importante colocá-las no campo da reflexão, num contexto histórico/social. Olhar para a história (passado) para traçar metas futuristas. Posto isto, o trabalhador social precisa assumir o compromisso sendo sujeito de transformação e não objeto dela. Tarefa que exige tomada de consciência de seu papel sobre a realidade. Freire (2018, p. 63) afirma que "Por isso, o trabalhador social não pode ser um homem neutro frente ao mundo, um homem neutro frente à desumanização ou humanização, frente à permanência do que já não representa os caminhos do humano ou à mudança destes caminhos".

A postura de um trabalhador social compromissado é aquela que busca quebrar uma estrutura social que oprime, segrega, discrimina as pessoas. É necessário reagir contra aos modelos dominantes que visam uma antimudança, apresentam uma visão acrítica e lutam para manter o status quo. A esse respeito, Freire comenta que o trabalhador social não pode temer a liberdade, a comunicação e a emancipação humana, pelo contrário, sua ação deve ser pautada no diálogo, numa busca constante pelo conhecimento para problematizar as forças Revista de Estudos em Educação e Diversidade. v. 1, n. 1, p. 111-117, jul./set. 2020. 


\section{Revista de Estudos em Educação e Diversidade}

REED

místicas que mantem o estado das coisas numa dada sociedade e desmistificá-la. A mudança é vista como necessária e, cada homem deve assumir a sua parte para alcançar a mudança na totalidade.

Além disto, Freire também enfatiza a importância de o trabalhador social buscar conscientizar o povo de suas reais necessidades. Sob este aspecto, o autor apresenta a mudança cultural como uma dimensão a ser analisada, em especial, a percepção que se tem da realidade para evitar uma visão acrítica e simplista do mundo. As estruturas só poderão ser mudanças mediante uma reflexão crítica, para assim, efetivar uma transformação que contemple um bem estar social. Dessa maneira, consoante o autor, o papel do trabalhador social é de combater a realidade desumanizante.

No quarto e último capítulo do livro, Freire apresenta o processo de alfabetização de adultos como caminho possível para a conscientização, pois ela favorece o ato criador. É pertinente enfatizar que o autor traz as constatações da ação educativa como necessária para reflexão. $\mathrm{O}$ ato de ensinar, vai muito mais além de uma mera exposição de conteúdos estruturados. É no ato de ensinar que o docente tem a oportunidade de valorizar a vocação ontológica do ser. Assim, favorecer as condições necessárias para o sujeito criar, recriar, decidir, transformar a sua realidade.

O ímpeto criador do homem que dará a condição dele participar da formação de cada época histórica da sociedade. Se ver num mundo em transição e ser capaz de atuar nele. De lutar por um mundo mais humano, mais democrático e mais livre. Ainda com confluência com esse processo, Freire aponta que o caminho para o homem tomar consciência do seu papel é pela educação, através de um método dialógico, crítico, participante, que o estimule a ser autor do próprio destino.

Contudo, para isto, um professor, como profissional da educação, necessita se enganar política e socialmente para perceber as suas possibilidades de ação e romper com as estruturas sociais que segregam, discrimina, oprimem, excluem, dentre outras. Partindo dessa premissa, romper com práticas antidialógicas, desesperançosas, desprovidas de amor, de humildade e confiança.

Freire traz o analfabetismo como uma forma de manter a alienação e que deve ser substituída por uma formação para a consciência crítica. Surge assim, a necessidade de investir na alfabetização, na formação do professor alfabetizador e coordenadores escolares, bem como investir nos locais e métodos de aprendizagens. Aponta o círculo de cultura como o caminho do "levantamento do universo vocabular" do estudante, a "seleção de palavras 


\section{Revista de Estudos em Educação e Diversidade}

geradoras", a "criação de situações sociológicas", as "fichas auxiliares" e "ampliação". Seu caminho metodológico de alfabetização apoia-se na realidade, em outros termos, apresenta uma educação contextualizada com a realidade do educando.

Em suma, o livro apresenta a educação como um ato de conhecer e conscientizar, criar e recriar, libertar e transformar. Assim sendo, todo profissional da educação deve ser comprometido com a sociedade e com o povo que a compõe. É tarefa do educador provocar transformações na sociedade dentro das possibilidades de sua profissão. Para isso, é necessário empreender esforços e compromisso com o futuro dos/as estudantes e do país.

\section{Referências}

FREIRE, Paulo. Educação e Mudança. Tradução de Lilian Lopes Martins. 39 ed. Rio de Janeiro/São Paulo: Paz e Terra, 2018.

Recebido em: 19 de agosto de 2020.

Aprovado em: 20 de setembro de 2020 . 